\title{
Association between fragmented QRS and postprocedural rhythm disturbances in patients who underwent transcatheter aortic valve implantation
}

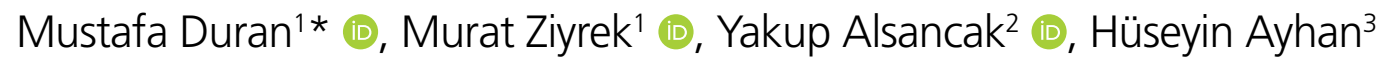

\section{SUMMARY}

INTRODUCTION: According to recent studies, the rate of atrioventricular block requiring permanent pacing in patients following transcatheter aortic valve implantation varied between $5.7 \%$ and $42.5 \%$. Fragmented QRS is a useful marker of myocardial scar and can predict adverse cardiac events. In this study, we examined association between fragmented QRS and postprocedural rhythm disturbances and the need for permanent pacing in patients who underwent transcatheter aortic valve implantation.

OBJECTIVE: In this study, we examined association between fragmented QRS and postprocedural rhythm disturbances and the need for permanent pacing in patients who underwent transcatheter aortic valve implantation' sentence is enough for it.

METHODS: We retrospectively analyzed standard 12-lead electrocardiographic recordings of 124 consecutive patients in whom a CoreValve prosthesis was implanted. We examined 12-lead electrocardiogram before and after procedure along with one- and six-month follow-up. We documented QRS fragmentation and postprocedural rhythm disturbances.

RESULTS: There was a significant increase in the frequency of left bundle branch block, $(21.1$ versus $0 \%, p<0.05)$ and the incidence of atrioventricular blocks requiring permanent pacing (21.1 versus $0 \%, p<0.05)$ following transcatheter aortic valve implantation in patients whose preprocedural electrocardiogram recordings revealed fragmented QRS compared to those without fragmented QRS. Based our collected data, the presence of QRS fragmentation in anterior derivations was the only independent factor associated with postprocedural rhythm disturbances (B-value 0.217 ; OR 0.805; 95\% Cl 0.136-4.78; $p=0.004$ ).

CONCLUSION: Our data showed an increased risk for the development of new-onset left bundle branch block and atrioventricular blocks following transcatheter aortic valve implantation in patients whose baseline electrocardiogram recordings demonstrated QRS fragmentation.

KEYWORDS: Aortic valve stenosis. Arrhythmias, cardiac. Transcatheter Aortic Valve Replacement.

\section{INTRODUCTION}

Transcatheter aortic valve implantation (TAVI) has emerged as a novel therapeutic option for patients who are considered to be ineligible for open surgery ${ }^{1}$. However, postprocedural complications including rhythm disturbances and the need for permanent pacing are common ${ }^{2}$.

\footnotetext{
${ }^{1}$ Konya City Hospital, Department of Cardiology - Konya, Turkey.

${ }^{2}$ Necmettin Erbakan University, Medicine Faculty, Department of Cardiology - Konya, Turkey.

${ }^{3}$ Atilim University, Medicine Faculty, Department of Cardiology - Ankara, Turkey.

*Corresponding author: drmustafaduran44@gmail.com

Conflicts of interest: the authors declare there are no conflicts of interest. Funding: none.

Received on June 29, 2021. Accepted on August 01, 2021
} 
Fragmented QRS complex (fQRS) is frequently seen on routine electrocardiographic (ECG) recordings with narrow or wide QRS complexes ${ }^{3}$. Prognostic significance of QRS fragmentation for predicting adverse cardiac events was demonstrated in previous studies ${ }^{4-6}$.

In this study, we aimed to investigate the predictive role of $\mathrm{fQRS}$ in the occurrence of rhythm disturbances and the need for permanent pacing in patients undergoing TAVI.

\section{METHODS}

We retrospectively analyzed standard 12-lead electrocardiographic recordings of 124 consecutive patients in whom a CoreValve prosthesis (Medronic Inc., Minneapolis, USA) was implanted. Patients having bundle branch block, including left bundle branch block (LBBB), incomplete or complete right bundle branch block (RBBB), or QRS duration $\geq 120 \mathrm{msec}$ in baseline ECG, and patients with permanent pacing were excluded from the study.

Demographic and clinical characteristics of patients and procedural variables were retrospectively analyzed. Preprocedural and the first and sixth months postprocedural ECG recordings were evaluated. Patients were divided into two groups based on the presence or absence of fQRS in the preprocedural ECGs. The presence of rhythm and types of rhythm disturbances were defined according to the AHA/ ACCF/HRS recommendations for the standardization and interpretation of the $\mathrm{ECG}^{7}$. Any of the rhythm disturbances occurring within the first 48 hours after TAVI are accepted as temporary, and those persisting more than 48 hours as permanent. ECG measurements were performed by a cardiologist who was blind to the patient data and verified by a second physician to avoid errors in measurements. Definition of fQRS was made according to previous studies ${ }^{8}$. Informed consent was obtained from all patients in accordance with a protocol approved by the Ethics Committee of Ankara Ataturk Training and Research Hospital (approval number: 26379996-102).

\section{Statistical analysis}

Statistical analyses were conducted using SPSS version 20.0 (SPSS Inc., USA). Data were expressed as mean \pm SD for continuous variables and as counts and percentages for categorical variables. Differences were considered statistically significant at $\mathrm{p}<0.05$. Fitness to the normal distribution was analyzed with the Kolmogorov-Smirnov test. Student's $t$-test and MannWhitney $U$ tests were used for comparison of continuous variables, and chi-square and Fisher's exact tests were used for comparison of categorical variables. Binary logistic regression analysis was performed to explore independent factors associated with rhythm disturbances.

\section{RESULTS}

Of the 124 patients initially screened, 24 patients whose baseline ECG recordings demonstrated wide QRS (QRS>120 msec) were excluded, leaving 100 patients for analysis. According to our study, 71 patients whose baseline ECG demonstrated QRS fragmentation at least in one derivation formed fQRS $(+)$ group and 29 patients whose baseline ECG did not demonstrate QRS fragmentation formed fQRS(-) group. A comparison of baseline clinical and demographic characteristics of both groups is provided in Table 1. Based on our data, male gender $(52.1$ versus $34.5 \%, \mathrm{p}<0.05)$ and calculated Society of Thoracic Surgeons scores ( $7.3 \pm 1.7$ versus $6.5 \pm 1.3, \mathrm{p}<0.05)$ were significantly higher in $\mathrm{fQRS}(+)$ group compared with $\mathrm{fQRS}(-)$ group. In addition, there were significantly lower estimated left ventricular ejection fraction ( 45 versus $65 \%$, $\mathrm{p}<0.001)$ and higher rates of the New York Heart Association (NYHA) classes (NYHA class III; 57.7 versus $41.4 \%$ and NYHA class IV; 26.8 versus $10.3 \%, \mathrm{p}<0.001)$ in fQRS $(+)$ group compared with fQRS(-) group. Although baseline ECG findings were comparable between the two groups, preprocedural heart rate was significantly lower in fQRS(+) group compared with fQRS(-) group $(70.8 \pm 13.5$ versus $77.4 \pm 13.3, \mathrm{p}<0.05)$.

A comparison of procedural variables and postprocedural rhythm disturbances is given in Table 2. Both groups had similar procedural characteristics. Regarding rhythm disturbances, 39 of 71 patients with fQRS developed temporary rhythm disturbances during hospitalization. However, only 4 of 29 patients without fQRS developed temporary rhythm disturbances. Furthermore, 28 of 71 patients with fQRS and 1 of 29 patients without fQRS developed permanent rhythm disturbances. After implantation of the device, permanent pacing was required in $10(10 \%)$ patients due to complete atrioventricular (AV) block.

Due to the loss of 10 patients, outcomes of 1 - and 6-month follow-up were based on data of 90 patients: 62 patients in $\mathrm{fQRS}(+)$ and 28 patients in fQRS(-) group. The difference in permanent rhythm disturbances was also maintained in 1 - month and 6-month follow-up (37.1 versus $0 \%$ and 38.7 versus $0 \%$; $<0.0001$ ). Binary logistic regression analysis provided that the presence of QRS fragmentation in anterior derivations was the only independent factor associated with postprocedural conduction abnormalities (Table 3). 
Table 1. Comparison of baseline characteristics of fragmented QRS (+) and fragmented QRS (-) groups.

\begin{tabular}{|c|c|c|c|}
\hline & fQRS $(+)(n=71)$ & fQRS (-) (n=29) & p-value \\
\hline Age (years) & $76.5 \pm 8.6$ & $79.1 \pm 5.2$ & 0.078 \\
\hline Male gender, n (\%) & $37(52.1)$ & $10(34.5)$ & 0.045 \\
\hline Coronary artery disease, $\mathrm{n}(\%)$ & $47(64.8)$ & $15(51.7)$ & 0.254 \\
\hline Diabetes mellitus, n (\%) & $26(36.6)$ & $10(34.4)$ & 0.845 \\
\hline Hypertension, n (\%) & $54(76.0)$ & $21(72.4)$ & 0.758 \\
\hline COPD, n (\%) & $52(73.2)$ & $16(55.2)$ & 0.079 \\
\hline Atrial fibrillation, $\mathrm{n}(\%)$ & $29(40.8)$ & $10(34.48)$ & 0.495 \\
\hline$\beta$-Blocker therapy preoperative $(n \%)$ & $44(61.9)$ & $17(58.62)$ & 0.678 \\
\hline Logistic EuroScore & $29.9 \pm 9.6$ & $28.5 \pm 9.7$ & 0.509 \\
\hline STS score & $7.3 \pm 1.7$ & $6.5 \pm 1.3$ & 0.035 \\
\hline \multicolumn{4}{|l|}{ NYHA class } \\
\hline NYHA class II, n (\%) & $11(15.5)$ & $14(48.3)$ & $<0.001$ \\
\hline NYHA class III, n (\%) & $41(57.7)$ & $12(41.4)$ & 0.046 \\
\hline NYHA class IV, n (\%) & $19(26.8)$ & $3(10.3)$ & $<0.001$ \\
\hline Ejection fraction (\%/ median, IQR) & $45(35-60)$ & $65(55-65)$ & $<0.001$ \\
\hline AVA $\left(\mathrm{cm}^{2}\right)$ & $0.69 \pm 0.11$ & $0.71 \pm 0.08$ & 0.064 \\
\hline Aortic peak gradient $(\mathrm{mm} \mathrm{Hg})$ & $77.4 \pm 26.8$ & $79.9 \pm 23.5$ & 0.658 \\
\hline Aortic mean gradient $(\mathrm{mm} \mathrm{Hg})$ & 47.3. \pm 14.9 & $49.1 \pm 16.4$ & 0.861 \\
\hline Heart rate (bpm) & $70.8 \pm 13.5$ & $77.4 \pm 13.3$ & 0.034 \\
\hline P wave duration (msec) & $89.03 \pm 10.75$ & $85.75 \pm 9.31$ & 0.498 \\
\hline PR interval (msec) & $142.06 \pm 17.86$ & $139.03 \pm 15.56$ & 0.297 \\
\hline QRS duration (msec) & $106.44 \pm 3.14$ & $103.16 \pm 5.87$ & 0.382 \\
\hline corrected QT interval (msec) & $398 \pm 13.55$ & $387 \pm 10.85$ & 0.078 \\
\hline AV block, n (\%) & $11(15.49)$ & $4(13.79)$ & 0.876 \\
\hline
\end{tabular}

fQRS: fragmented QRS; COPD: chronic obstructive pulmonary disease; NYHA: New York Heart Association; STS: Society of Thoracic Surgeons; AVA: aortic valve area, bpm: beats per minute; AV: atrioventricular. Bold values indicate statistical significance at $p<0.05$.

\section{DISCUSSION}

The main finding of this study is the presence of fQRS on surface ECG prior to the TAVI, which is a strong predictor for the development of rhythm disturbances and the need for permanent pacemaker implantation.

TAVI is a less invasive and safe therapeutic alternative in patients who are at very high surgical risk or in whom there are contraindications to surgical aortic valve replacement. On the other hand, life-threatening complications including stroke, paravalvular leak, and rhythm disturbances that require permanent pacing still persist ${ }^{9}$. In terms of postprocedural complications of TAVI, AV and intraventricular conduction disorders are still the most frequent adverse events ${ }^{10}$.

Due to the importance of postprocedural rhythm disturbances, several studies were investigating the predictive risk factors for the development of rhythm disturbances in patients undergoing TAVI. According to those studies, septal wall thickness, noncoronary cusp thickness, preexisting RBBB, depth of valve implantation within the left ventricular outflow tract, postimplant prosthesis expansion, and the type of prosthesis were independent risk factors for this complication ${ }^{11-14}$.

According to our study, there was a strong association between QRS fragmentation and postprocedural rhythm disturbances, including new-onset LBBB and complete $A V$ block. In addition, the incidence of AV blocks requiring permanent pacing was higher in patients with fQRS than patients with non-fQRS ( 11 versus $0 \%, \mathrm{p}<0.05)$. Furthermore, there was a strong relationship between the number of ECG leads with FQRS and the incidence of rhythm disturbances and this relation reached statistical 
Table 2. Procedural characteristics and postprocedural rhythm disturbances of fragmented QRS (+) and fragmented QRS (-) groups.

\begin{tabular}{|c|c|c|c|c|}
\hline & fQRS $(+)(n=71)$ & fQRS $(-)(n=29)$ & p-value \\
\hline \multicolumn{2}{|c|}{ Single valve implantation, $\mathrm{n}(\%)$} & $66(92.9)$ & $28(96.5)$ & 0.014 \\
\hline \multirow{2}{*}{ Approach, n (\%) } & Transfemoral & $67(94.37)$ & $27(93.11)$ & 0.684 \\
\hline & Transapical & $4(5.63)$ & $2(6.89)$ & 0.698 \\
\hline \multirow{2}{*}{ Implantation depth (mm) } & $\mathrm{LCC}(\mathrm{mm})$ & $6.37 \pm 2.54$ & $6.32 \pm 2.53$ & 0.601 \\
\hline & $\mathrm{NCC}(\mathrm{mm})$ & $6.86 \pm 2.33$ & $6.89 \pm 2.67$ & 0.706 \\
\hline \multicolumn{2}{|l|}{ Predilatation, n (\%) } & $53(74.64)$ & $20(71.42)$ & 0.804 \\
\hline \multicolumn{2}{|l|}{ Postdilatation, n (\%) } & $10(14.08)$ & $4(13.79)$ & 0.901 \\
\hline \multicolumn{2}{|l|}{ Prosthesis size (mm) } & $27.30 \pm 2.66$ & $26.85 \pm 2.46$ & 0.181 \\
\hline \multicolumn{2}{|c|}{ Ratio of prosthesis size to annulus size } & $1.08 \pm 0.02$ & $1.07 \pm 0.03$ & 0.681 \\
\hline \multicolumn{2}{|c|}{ Intraoperative peak pressure gradient $(\mathrm{mm} \mathrm{Hg})$} & $16.7 \pm 8.12$ & $18.7 \pm 6.83$ & 0.156 \\
\hline \multicolumn{2}{|c|}{ Intraoperative mean pressure gradient $(\mathrm{mm} \mathrm{Hg})$} & $9.5 \pm 5.2$ & $9.9 \pm 3.6$ & 0.295 \\
\hline
\end{tabular}

\begin{tabular}{l|c|c|c}
\multicolumn{4}{c}{ Postprocedural temporary rhythm disturbances } \\
\hline No rhythm disturbance $(n)$ & $\begin{array}{c}\text { Total patients } \\
(n=100)\end{array}$ & $\begin{array}{c}\text { fQRS }(+) \text { group } \\
(n=71)\end{array}$ & $\begin{array}{c}\text { fQRS (-) group } \\
(n=29)\end{array}$ \\
\hline Temporary RBBB $(n)$ & 57 & 32 & 25 \\
\hline Temporary LBBB $(n)$ & 4 & 2 & 2 \\
\hline Temporary first-degree AV block & 27 & 25 & 2 \\
\hline Temporary second-degree AV block & 17 & 15 & 2 \\
\hline Temporary third-degree AV block & 0 & 0 & 0 \\
\hline
\end{tabular}

\begin{tabular}{|c|c|c|c|}
\hline \multicolumn{4}{|c|}{ Postprocedural permanent rhythm disturbances } \\
\hline & $\begin{array}{l}\text { Total patients } \\
\quad(\mathrm{n}=100)\end{array}$ & $\begin{array}{c}\text { fQRS }(+) \text { group } \\
(n=71)\end{array}$ & $\begin{array}{c}\text { fQRS (-) group } \\
(n=29)\end{array}$ \\
\hline No rhythm disturbance $(\mathrm{n})$ & 71 & 43 & 28 \\
\hline Permanent RBBB $(n)$ & 3 & 2 & 1 \\
\hline Permanent LBBB (n) & 15 & 15 & 0 \\
\hline Permanent first-degree AV block & 15 & 14 & 1 \\
\hline Permanent second-degree AV block & 0 & 0 & 0 \\
\hline Permanent third-degree AV block & 11 & 11 & 0 \\
\hline \multicolumn{4}{|c|}{ Postprocedural 1-month follow-up } \\
\hline & $\begin{array}{l}\text { Total patients } \\
\quad(\mathrm{n}=90)\end{array}$ & $\begin{array}{c}\text { fQRS (+) group } \\
(\mathrm{n}=62)\end{array}$ & $\begin{array}{c}\text { fQRS (-) group } \\
(\mathrm{n}=28)\end{array}$ \\
\hline No rhythm disturbance $(\mathrm{n})$ & 67 & 39 & 28 \\
\hline Permanent RBBB (n) & 2 & 2 & 0 \\
\hline Permanent LBBB (n) & 11 & 11 & 0 \\
\hline Permanent first-degree AV block & 14 & 14 & 0 \\
\hline Permanent second-degree AV block & 0 & 0 & 0 \\
\hline Permanent third-degree AV block & 10 & 10 & 0 \\
\hline
\end{tabular}


Table 2. Continuation.

\begin{tabular}{l|c|c|c}
\multicolumn{4}{c}{ Postprocedural 6-month follow-up } \\
\hline No rhythm disturbance $(n)$ & $\begin{array}{c}\text { Total patients } \\
(n=90)\end{array}$ & $\begin{array}{c}\text { fQRS (+) group } \\
(n=62)\end{array}$ & $\begin{array}{c}\text { fQRS }(-) \text { group } \\
(n=28)\end{array}$ \\
\hline Permanent RBBB $(n)$ & 66 & 38 & 28 \\
\hline Permanent LBBB $(n)$ & 3 & 3 & 0 \\
\hline Permanent firs-degree AV block & 11 & 11 & 0 \\
\hline Permanent second-degree AV block & 11 & 11 & 0 \\
\hline Permanent third-degree AV block & 0 & 0 & 0 \\
\hline
\end{tabular}

FQRS: fragmented QRS; LCC: left coronary cusp; NCC: noncoronary cusp; RBBB: right bundle branch block; LBBB: left bundle branch block; AV: atrioventricular.

Table 3. Data of binary regression analysis.

\begin{tabular}{l|c|c|c|c} 
& Beta value & Odds ratio & $95 \% \mathrm{Cl}$ & $\mathrm{p}$-value \\
\hline Age & 0.561 & 0.398 & $0.871-2.156$ & 0.065 \\
\hline Male gender & 0.231 & 0.167 & $0.451-1.542$ & 0.483 \\
\hline STS Score & 0.698 & 0.781 & $0.653-2.156$ & 0.078 \\
\hline Preprocedural ejection fraction & 0.327 & 0.349 & $0.642-2.256$ & 0.087 \\
\hline AVA & 0.611 & 0.472 & $0.486-1.459$ & 0.118 \\
\hline Baseline heart rate & 0.134 & 0.371 & $0.380-1.014$ & 0.569 \\
\hline Baseline PR interval & 0.498 & 0.287 & $0.135-1.816$ & 0.603 \\
\hline Fragmentation in anterior leads on baseline ECG & 0.217 & 0.805 & $1.036-4.78$ & 0.004 \\
\hline Baseline QT interval & 0.531 & 0.269 & $0.690-2.698$ & 0.517 \\
\hline Baseline QRS interval & 0.719 & 0.491 & $0.997-3.175$ & 0.071 \\
\hline Prosthesis size & 0.598 & 0.370 & $0.792-2.784$ & 0.089 \\
\hline
\end{tabular}

STS: Society of Thoracic Surgeons; AVA: aortic valve area. Bold values indicate statistical significance at $p<0.05$.

significance in anterior leads compared with inferior leads (84.1 versus $50 \%, \mathrm{p}<0.05$ ).

Although the exact mechanisms that cause the formation of fQRS are not fully understood, altered homogeneity of myocardial electrical activity as a result of myocardial fibrosis and/or ischemia is generally accepted as the underlying mechanism ${ }^{15,16}$. Recent studies also revealed the strong relationship between the presence of fQRS and severe aortic stenosis. According to a study conducted by Agac et al. ${ }^{17}$, the incidence of fQRS was found to be $46 \%$ in patients with severe aortic stenosis. In our study, there was a higher rate of fQRS in patients with severe aortic stenosis compared with their study (71 versus $46 \%$ ). The most plausible explanation was higher rates of comorbid conditions and lower rates of calculated ejection fraction in our study compared with their cohort.

In another study conducted by Ay et al. ${ }^{18}$, there was a strong association between $\mathrm{fQRS}$ and long-term survival in patients undergoing TAVI. Although outcomes of our study were comparable with their study, our study group consisted of higher rates of patients with fQRS than their study (71 versus $30.7 \%$ ). Due to exclusion of patients with a prior history of myocardial infarction, coronary bypass surgery, severe coronary lesions, and those with an ejection fraction $\leq 30 \%$ from their study, this difference was observed. They also investigated the relationship between the need for permanent pacing following TAVI and the existence of fQRS. According to their study, the need for permanent pacing in the long term was higher in patients with fQRS compared with patients without fQRS (8.3 versus $3.7 \%, \mathrm{p}=0.29)$. Compared with our study, the rate of permanent pacing was lower $(0.5$ versus $10 \%)$ in their study and the most plausible explanation was the difference in types of devices used for the procedure. In our study, all patients (100\%) underwent TAVI with the CoreValve prosthesis. However, only 26 (22.2\%) of 117 patients underwent TAVI with CoreValve prosthesis in their study. 


\section{CONCLUSIONS}

In conclusion, our data showed an increased risk for the development of new-onset LBBB and AV blocks in patients whose baseline ECG recordings demonstrated QRS fragmentation.

\section{AUTHORS" CONTRIBUTIONS}

MD: Conceptualization, Datacuration, Formal analysis, Writing-original draft.MZ: Data curation, Formal analysis, Writing-review \& editing. YA: Conceptualization, Writing-review \& editing. HA: Conceptualization, Data curation, Formal analysis, Writing - review \& editing.

\section{REFERENCES}

1. Cribier A, Eltchaninoff H, Bash A, Borenstein N, Tron C, Bauer $\mathrm{F}$, et al. Percutaneous transcatheter implantation of an aortic valve prosthesis for calcific aortic stenosis: first human case description. Circulation. 2002;106(24):3006-8. https://doi. org/10.1161/01.cir.0000047200.36165.b8

2. Lee MY, Yeshwant SC, Chava S, Lustgarten DL. Mechanisms of heart block after transcatheter aortic valve replacement cardiac anatomy, clinical predictors and mechanical factors that contribute to permanent pacemaker implantation. Arrhythm Electrophysiol Rev. 2015;4(2):81-5. https://doi.org/10.15420/ aer.2015.04.02.81

3. Das MK, Suradi H, Maskoun W, Michael MA, Shen C, Peng J, et al. Fragmented wide QRS on a 12-lead ECG: a sign of myocardial scar and poor prognosis. Circ Arrhythm Electrophysiol. 2008;1(4):258-68. https://doi.org/10.1161/ CIRCEP.107.763284

4. Korhonen P, Husa T, Konttila T, Tierala I, Mäkijärvi M, Väänänen $\mathrm{H}$, et al. Fragmented QRS in prediction of cardiac deaths and heart failure hospitalizations after myocardial infarction. Ann Noninvasive Electrocardiol. 2010;15(2):130-7. https://doi. org/10.1111/j.1542-474X.2010.00353.x

5. Das MK, Saha C, El Masry H, Peng J, Dandamudi G, Mahenthiran J, et al. Fragmented QRS on a 12-lead ECG: a predictor of mortality and cardiac events in patients with coronary artery disease. Heart Rhythm. 2007;4(11):1385-92. https://doi. org/10.1016/j.hrthm.2007.0

6. Pietrasik G, Goldenberg I, Zdzienicka J, Moss AJ, Zareba W. Prognostic significance of fragmented QRS complex for predicting the risk of recurrent cardiac events in patients with Q-wave myocardial infarction. Am J Cardiol. 2007; 100(4):583-6. https://doi.org/10.1016/j.amjcard.2007.03.063

7. Surawicz B, Childers R, Deal BJ, Gettes LS, Bailey JJ, Gorgels $A$, et al. American Heart Association Electrocardiography and Arrhythmias Committee, Council on Clinical Cardiology; American College of Cardiology Foundation; Heart Rhythm Society. AHA/ACCF/HRS recommendations for the standardization and interpretation of the electrocardiogram: part III: intraventricular conduction disturbances: a scientific statement from the American Heart Association Electrocardiography and Arrhythmias Committee, Council on Clinical Cardiology; the American College of Cardiology Foundation; and the Heart Rhythm Society. Endorsed by the International Society for Computerized Electrocardiology. J Am Coll Cardiol. 2009;53(11):976-81. https://doi.org/10.1016/j. jacc.2008.12.013

8. Das MK, Khan B, Jacob S, Kumar A, Mahenthiran J. Significance of a fragmented $\mathrm{QRS}$ complex versus a $\mathrm{Q}$ wave in patients with coronary artery disease. Circulation. 2006;113(21):2495-501. https://doi.org/10.1161/CIRCULATIONAHA.105.595892
9. Erkapic D, Kim WK, Weber M, Mollmann H, Berkowitsch A, Zaltsberg $\mathrm{S}$, et al. Electrocardiographic and further predictors for permanent pacemaker requirement after transcatheter aortic valve implantation. Europace. 2010;12(8):1188-90. https://doi.org/10.1093/europace/euq094

10. Urena M, Rodés-Cabau J. Managing heart block after transcatheter aortic valve implantation: from monitoring to device selection and pacemaker indications. Eurolntervention. 2015;11:W101-5. https://doi.org/10.4244/EIJV11SWA30

11. Piazza N, Nuis RJ, Tzikas A, Otten A, Onuma Y, García HG, et al. Persistent conduction abnormalities and requirements for pacemaking six months after TAVI. Eurolntervention. 2010;6(4):475-84. https://doi.org/10.4244/EIJ30V6I4A80

12. Baan J Jr, Yong ZY, Koch KT, Henriques JP, Bouma BJ, Vis MM, Cocchieri R, Piek JJ, de Mol BA. Factors associated with cardiac conduction disorders and permanent pacemaker implantation after percutaneous aortic valve implantation with the CoreValve prosthesis. Am Heart J. 2010;159(3):497-503. https://doi.org/10.1016/j.ahj.2009.12.009

13. Ferreira N, Caeiro D, Adão L, Oliveira M, Gonçalves H, Ribeiro $J$, et al. Incidence and predictors of permanent pacemaker requirement after transcatheter aortic valve implantation with a self-expanding bioprosthesis. Pacing Clin Electrophysiol. 2010;33(11):1364-72. https://doi.org/10.1111/j.15408159.2010.02870.x

14. Roten L, Wenaweser P, Delacretaz E, Hellige G, Stortecky S, Tanner $\mathrm{H}$, et al. Incidence and predictors of atrioventricular conduction impairment after transcatheter aortic valve implantation. Am J Cardiol. 2010;106(10):1473-80. https:// doi.org/10.1016/j.amjcard.2010.07.012

15. Lesh MD, Spear JF, Simson MB. A computer model of the electrogram: what causes fractionation? J Electrocardiol. 1988;21:S69-73. https://doi.org/10.1016/00220736(88)90061-1

16. Başaran $Y$, Tigen K, Karaahmet T, Işıklar I, Çevik C, Gürel E, et al. Fragmented QRS complexes are associated with cardiac fibrosis and significant intraventricular systolic dyssynchrony in nonischemic dilated cardiomyopathy patients with a narrow QRS interval. Echocardiography. 2011;28(1):62-8. https://doi. org/10.1111/j.1540-8175.2010.01242.x

17. Ağaç MT, Korkmaz L, Bektas $H$, Acar Z, Erkan $H$, Kurt IH, et al. Increased frequency of fragmented QRS in patients with severe aortic valve stenosis. Med Princ Pract. 2014;23(1):66-9. https://doi.org/10.1159/000355474

18. Ay NK, Enhos A, Ay Y, Bakhshaliyev N, Nadir A, Karacop E, et al. The prognostic value of fragmented QRS in patients undergoing transcatheter aortic valve implantation. J Electrocardiol. 2018;51(6):923-7. https://doi.org/10.1016/j. jelectrocard.2018.07.015 